\title{
Article
}

\section{Providing high-quality care at the end of life: the role of education and guidance}

Dobson, Jill

Available at http://clok.uclan.ac.uk/20729/

Dobson, Jill (2017) Providing high-quality care at the end of life: the role of education and guidance. British Journal of Nursing, 26 (20). pp. 1116-1120. ISSN 0966-0461

It is advisable to refer to the publisher's version if you intend to cite from the work.

For more information about UCLan's research in this area go to

http://www.uclan.ac.uk/researchgroups/ and search for < name of research Group>.

For information about Research generally at UCLan please go to http://www.uclan.ac.uk/research/

All outputs in CLoK are protected by Intellectual Property Rights law, including Copyright law. Copyright, IPR and Moral Rights for the works on this site are retained by the individual authors and/or other copyright owners. Terms and conditions for use of this material are defined in the policies page. 


\section{British Journal of Nursing \\ End of Life guidance in clinical practice \& the lack of End of Life care education for clinical staff \\ --Manuscript Draft--}

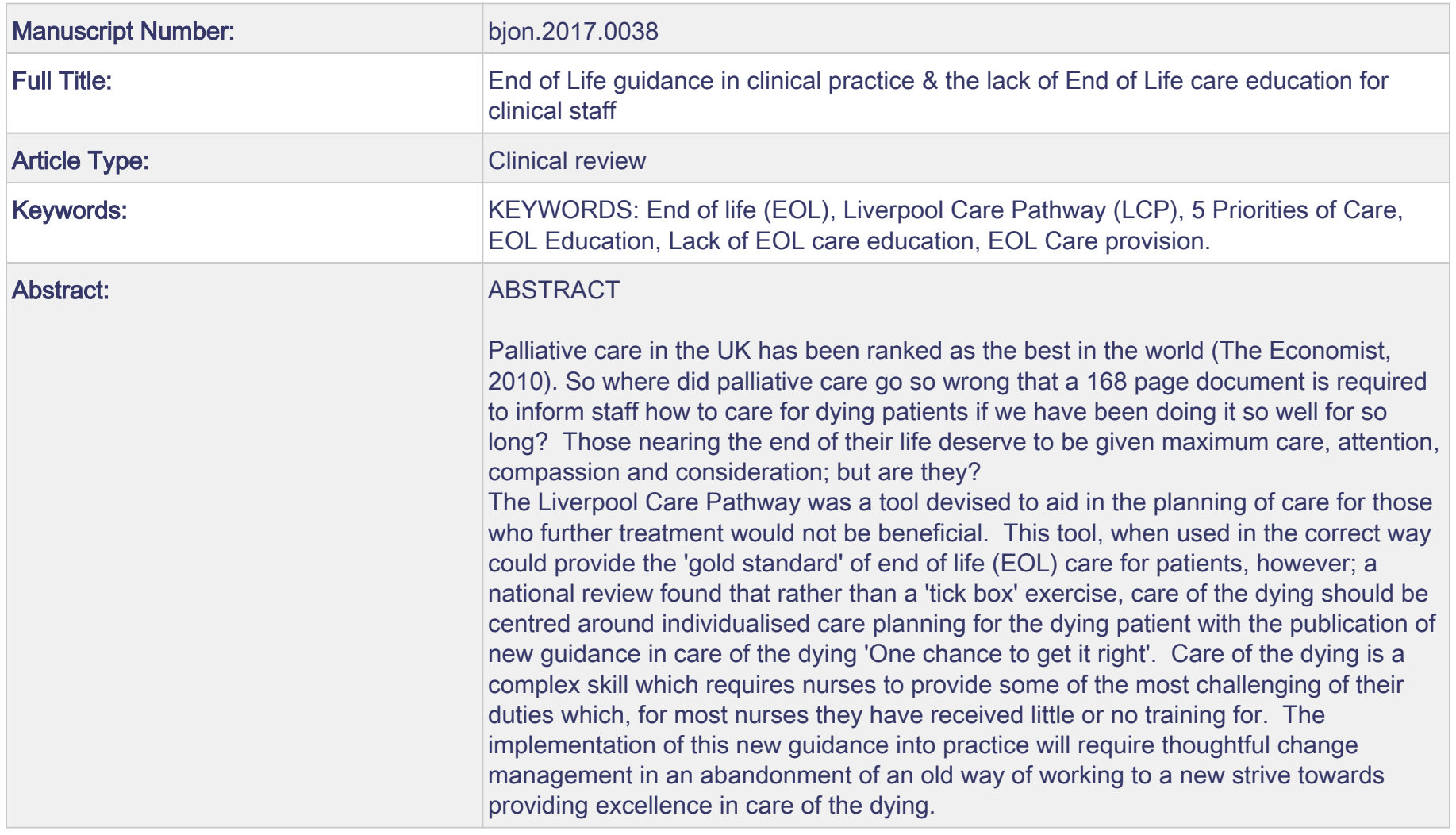




\section{ABSTRACT}

Palliative care in the UK has been ranked as the best in the world (The Economist, 2010).

So where did palliative care go so wrong that a 168 page document is required to inform staff how to care for dying patients if we have been doing it so well for so long? Those nearing the end of their life deserve to be given maximum care, attention, compassion and consideration; but are they?

The Liverpool Care Pathway was a tool devised to aid in the planning of care for those who further treatment would not be beneficial. This tool, when used in the correct way could provide the 'gold standard' of end of life (EOL) care for patients, however; a national review found that rather than a 'tick box' exercise, care of the dying should be centred around individualised care planning for the dying patient with the publication of new guidance in care of the dying 'One chance to get it right'. Care of the dying is a complex skill which requires nurses to provide some of the most challenging of their duties which, for most nurses they have received little or no training for. The implementation of this new guidance into practice will require thoughtful change management in an abandonment of an old way of working to a new strive towards providing excellence in care of the dying.

KEYWORDS: End of life (EOL), Liverpool Care Pathway (LCP), 5 Priorities of Care, EOL Education, Lack of EOL care education, EOL Care provision. 


\section{INTRODUCTION}

Death, dying and bereavement create diverse, individualised experiences for every person as they are exclusive, unique processes; as each have differing personalities, managing skills and coping mechanisms in response to loss and no experience will be the same as the previous (Pentaris, 2013). As Dame Cicely Saunders (2005) suggested, the dying are the only ones who know how to die in relation to their character, personality and background. As technology advanced in the 1900s, the tendency to provide heroic actions inhibited the attention provided to end of life care and left patients and their families feeling neglected (Chiplansky, 2015).

When the death of a patient occurs in the hospital setting, relatives, friends and loves ones frequently turn to the healthcare professional for help and support; regrettably, healthcare professionals are not always confident in dealing with this sensitive area (Morris \& Corbett, 2011). The reasons for this are numerous; in many clinical areas, death is unexpected and death is not recognised, early death is seen as a failure to many healthcare professionals and therefore when cure is not achieved, the prospect of their patient dying becomes an unwanted concept (Kirchoff, 2000; Neuberger 2003 cited in Ellershaw \& Ward, 2003; Sleeman, 2013).

\section{LIVERPOOL CARE PATHWAY (LCP)}

The LCP was developed in the 1990's using a tried and tested Integrated Care Pathway as part of a project. This project occurred at the Royal Liverpool and Broadgreen Hospitals and the Marie Curie Hospice in Liverpool, based on care of the dying within the hospice setting with the aim to transfer best practice to other settings (Handy et al, 2013). The LCP was identified as best practice within National Institute of Health and Care Excellence (NICE) guidance in 2004 and was included in the EOL Care strategy as a tool to assist in the care of the dying in 2008. 
Just some four years later, came controversy and increased media coverage regarding the LCP and its use within clinical practice and was subject to an independent review 'More care, less pathway' by Julia Neuberger in 2013.

This negative media coverage had a huge impact within practice and the use of the LCP became unfeasible as the families of those patients who were cared for with the application of the LCP had been influenced by the negative media and did not want any involvement of the pathway in the care of their loved one (Chinthalpalli, 2013).

The fact that there were many positive reflections on the LCP that were disregarded such as those from Dr Bunn who is a palliative care pharmacist. Dr Bunn declared that before the LCP there was no direction in how to care for the dying. He stated that despite the negative media the LCP received, it is an excellent tool and passionately believed that the LCP benefits patient care (Bunn, 2014).

Neuberger's review concluded that the LCP as a document could be viewed as a 'tick box exercise' and was not individualised enough to meet the needs of all dying patients and that the document was being used inappropriately. Overall there was little criticism of the document on the whole but established that it was an educational issue where practitioners had initiated and implemented the document incorrectly (Wrigley, 2014). Not unexpectedly, Neuberger's review echoed similar themes of those presented in the Francis report (2013) and highlights the importance of significant emphasis on caring and compassion for those dying and the essential requirement of EOL training and education.

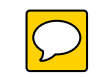

Despite the damaging attention the LCP received and its subsequent removal from use in clinical practice, there are those practitioners who feel that the LCP was fit for purpose and it met the needs of dying patients if utilised in the correct way (Chinthalpalli, 2013; Wrigley, 2014). Wrigley (2013) argued that rather than abandoning the LCP, it would be better to improve training with continued research in end-of-life care. Neuberger herself stated in the review 'In the right hands', the Liverpool care pathway can provide a model of good practice 
for the last days and hours of life for many patients, however, it is clear that, in the wrong hands, the LCP is a reason for poor care and it was removed from use in practice (Neuberger, 2013).

This argument was highlighted by the public engagement performed by the Leadership Alliance for the Care of Dying People (LACDP, 2014). It is appropriate to explore the guidance published in response to the Neuberger report (2013), 'One chance to get it right' (2014), in an aim to explore the current guidance available for healthcare staff and those caring for the dying with the priorities of delivering high quality EOL care.

\section{'ONE CHANCE TO GET IT RIGHT’ (LACDP 2014) - 5 PRIORITIES FOR CARE OF THE DYING}

In response to the Neuberger report (2013), 21 national organisations came together to form the Leadership Alliance for the Care of Dying People (LACDP). The purpose of the LACDP was to provide a united act to assure improvements in uniformity and consistency of EOL care in England.

A key part of the LACDP's work was the creation of the Priorities for Care, which are envisioned as the foundation of care for everyone in the last few days and hours of life, regardless of where the person is dying and this guidance would have to be very different to the LCP and how it had been used (LACDP, 2014). The priorities differ to each person and must be adapted to meet diverse needs and choices (LACDP, 2014). The first priority of the document is recognising dying, noted in the Neuberger report (2013), diagnosing imminent death is 'tricky' business. There are no prognostic indicators provided in 'One chance to get it right' for the recognition of dying patient and only acknowledge that there are tools and assessments available but there is insufficient evidence for the LACDP to endorse. Therefore, staff are expected to diagnose dying based on best judgement and communicate uncertainty regarding prognosis. Uncertainty can never be removed from the dying process, the need for good communication in the complexity in diagnosing dying needs to be confessed. Jones 
(2008) states that recognising dying is a skill that few junior doctors po:ss and highlights that increased EOL training is required instead of attempting to manage care which is declared 'TLC' or 'conservative management' and being uncertain of the true meaning of these terms and care being left to the imagination. Furthermore, Freemantle and Seymour (2012) found that in recognition of dying patients, it was necessary for staff to have the confidence to voice this opinion and that those who had more experience realised and recognised the dying phase earlier and prompted others in enabling patients to receive a comfortable and distress free experience as possible.

This second priority is nothing new as communication at the EOL has been researched and found to be an essential part of effective care (Sleeman 2013; National Institute for Clinical Excellence [NICE] 2013; General Medical Council [GMC] 2010). Sleeman (2013) declares that many doctors are reluctant to approach EOL discussions with patients as it denies them of hope, however; the opposite is true, open, honest discussions can empower patients to make decisions about their care and enhance rather than diminish hope. An individual plan of care is the final priority, which includes food and drink, symptom control and psychological, social and spiritual support, is agreed, co-ordinated and delivered with compassion (LACDP, 2014). This priority appears unambiguous and is something that healthcare professionals have been delivering for decades and the priority presents those principles found in Cicely Saunders Total Pain Theory (1993 cited in Mehta \& Chan, 2008). A close colleague of Saunders, Twycross, went on to transform Cicely's Total Pain theory, in inspiring the internationally approved standards for the relief of pain for those suffering with cancer formed in the 1980's by the World Health Organisation: The Three Step Ladder, and the first definition of palliative care reflects Cicely's Theory and Framework (Meldrum, 2005 cited in Seymor, 2012), this is the protocol still used in palliative practice today (Oransky, 2005). Those principles founded by Saunders over 50 years ago are still being presented as new guidance today. 
It is evident throughout the LACDP document that NICE Quality standards for EOL care (2013) and GMC Treatment and care towards the EOL (2010) are frequently referred to in specific areas of the guidance and it is acknowledged that the principles of the document are consistent with these previous documents. Considering the guidance and principles of the GMC and NICE, there was a vast array of data and material in reference to the care of the dying. It could be questioned why a new set of guidelines were required when it was all there beforehand and the new LACDP guidance is assembled from the previous published guidance.

Despite all the guidance possible, is the dying process always able to be a positive experience for all? Despite EOL tools, policy and guidance and excellent standards of care, is the notion of EOL care being romanticised? Lawton (2000) states that in her work with dying patients, she was unprepared for the experience of bodily decay, stench of incontinence, lethargy of patients, despondency and suffering of patients and their relatives and loved ones despite excellent care, warmth, humanity and professionalism of staff caring for the dying. She states that there is a great comfort in the belief that EOL care can be peaceful and dignified and that death is not prolonged unnecessarily; this is after all what we would want for ourselves and for those we love, but it is not always possible (Lawton, 2000).

It is evident that staff will now become heightened in their practice in care of the dying due to the current legislation changes and previous media attention, therefore what happens next for those caring for dying patients and what guidance is available for them in the interim whilst the five priorities are filtered into practice should be addressed.

\section{A PAUSE IN PRACTICE}

It could be viewed that until the LACDP (2014) priorities of care artuced in the guidance of care for the dying, there was a void in support for those caring for the dying and in the experiences of the dying. 
As the LCP has received such 'bad publicity' and has been poorly practised, it is envisaged that the new guidance should be embraced within practice and clinical staff will appreciate any guidance that will replace the ill-reputed LCP in aiding and assisting them to care for the dying. It is also important to consider that the new guidance must be supplemented with an awareness of ethical decision making and good communication of these decisions (Thorns \& Garrard 2003 cited in Ellershaw \& Wilkinson, 2013). Dr Ros Taylor agreed that education and support for staff was vital to the success of the new priorities of care (Stephenson, 2014).

It is a valid point to raise that staff may find the LCP a tool that is more helpful in care of the dying as the new guidance is less prescriptive in its five priorities and individualised care planning is assumed from staff and the document presupposes that staff will adopt individualised care planning and that they are capable of doing so. If staff are ill-educated or trained in the care of patients at the end of life, it is imagined that they may still rely on the principles of the LCP in their delivery and planning of EOL care. The LACDP (2014) has not suggested a single set of support resources but perm g organisations to work it out for themselves'. Sue Rogers, Chief Nurse at Sue Ryder argues that if people are still using the LCP, it shows a lack of awareness of what is required and that individualised care planning is required to meet the five priorities. Wrigley contends that those that do not work in a palliative speciality do not have the skills or expertise to fill in the gaps for themselves and what is the alternative - to invent it for themselves? (Wrigley, 2014). On that basis, it is applicable to examine the EOL education and training that exists for staff.

\section{LACK OF EOL EDUCATION FOR CLINICAL STAFF}

Over 50 million people die each year around the world and nurses are vital in delivering care to these individuals, yet many nurses have received little or no education in palliative or EOL care (Ferrell, Virani, Paice, Coyle \& Coyne, 2010). Palliative care in the UK has been ranked as the best in the world (The Economist, 2010) and hundreds of thousands of NHS and social care staff deal in some way with people at the end of their lives, yet many have had little or no 
formal training in this area and still despite being a problem for decades, for many doctors, death and breaking bad news may be seen as a failure (Addicot and Ashton 2010; Jeffery, 2006). This attitude to dying presents the possibility that some healthcare professionals see death as defeat resulting in heroic attempts to prolong life, often at great costs (Taylor, 2014). In a survey of Royal College $\int$ Jursing members, $11 \%$ said that were unable to deliver the right level of care to patients, with $59 \%$ stating that patients wishes had not been fulfilled in the last 6 months; when asked why those wishes could not be fulfilled, reasons given included lack of time and lack of training. Despite this, $25 \%$ of the nurses stated they had never received any specific training either before qualifying or since commencing their post (Ford, 2014).

The NHS EOL care programme (2008) found that healthcare professionals received little or basic communication skills training despite having involvement in EOL care, meaning that 1 in 4 nurses do not feel comfortable in raising the subject of death with patients. Claire Henry, director of the NHS National EOL Care Programme, said EOL care scenarios should be included in pre-registration nurse training modules on communication skills (Ford, 2014).

As a lecturer in nursing, I could not agree more; the evident need of EOL training and communication skills training highlighted, prompts discussion of why these subjects are not compulsory elements of nurse training. This is mirrored in the statement of Wood \& Salter (2013) who agree education and guidance should be provided for hospital staff at all levels in communication at the EOL and delivering care holistically for these individuals - preferably within a classroom environment, rather than scarcely captured within the constraints of clinical practice. The training should be a crucial element of medical and nursing undergraduate curricula, while health trusts should consider opportunities for rotations and shadowing in hospices for staff most in contact with older patients and those with terminal illness (Wood \& Salter 2013). Practice experience indicates that if there is one sure thing that nurses will 
require in practice, it is the knowledge and skills of how to care for those in the last hours of life and how to communicate with them and the people they love.

The EOL Care Strategy (2008) highlighted the need for developments in training and recognised the minimum levels of knowledge and skills that should be possessed by different professionals. Individuals providing EOL care ought to be able to communicate with patients, loved ones and carers about their prognosis, needs, hopes and expectations with compassion, (Payne et al, 2009). Hughes-Hallet et al, (2012) guage how we care for the dying as a moral indicator of the health service and a responsible society, judged by the dignity and respect showed for all people in all areas of all ages. Professionals do not often have the confidence or skill to attempt this, and this should be a main emphasis of training support (DH, 2008). With an ageing society and deaths likely to increase over the next 20 years, nurses will unquestionably be involved in delivering EOL care and if nurses are to become engaged with dying patients and become increasingly more confident, training and educational strategies will need to develop quickly in meeting the needs of the future dying population. Storey (2011 cited in Sprinks 2011), mentions that many nurses are capable of EOL care but most are worried of upsetting patients. Storey continues that staff need EOL training early on how to have sensitive conversations. Many doctors have been reluctant to deviate from a stringent medical model and explore psychological issues in the anxiety that it will release an emotional barrage that they cannot deal with (Maguire \& Pitceathly, 2002). The EOL care strategy (DH 2008), states that different models of education will be required, given the array of individuals participating in the delivery of EOL care and they endorsed elearning as a potential resolution for reaching a large workforce. However, as a tutor of communication skills, this method of developing skills would appear to be a tick-box exercise and would not achieve the desired outcome as the sensitive area of EOL communication skills requires face-to-face communication through experiential learning. Chiplasky (2015) 
recommends continuing education and core EOL competencies and revision of EOL texts which will offer a move towards an improved future in the delivery of EOL care.

It should be acknowledged and considered that EOL education and University courses are targeted at those who were specialist in EOL which would defeat the object of improving EOL care as those being educated are presumably those already competent and wanting to improve further. The criteria for inclusion on courses should be targeted and made easier to apply for those who really need it, as proposed in a study undertaken by Duxbury et al, (2011) who suggested EOL care training has to be available to all as it is 'everybody's business'; communication skills training being of uppermost importa. The study also recommends that training should incorporate competencies which must be assessed and achieved and that EOL training should be provided pre-and post registration for nurses and that access to EOL training must be improved for those at the forefront in both specialist and generalist areas. Education and training in EOL in most NHS trusts is still not mandatory (National EOL care Intelligence Network, 2012). This denotes that training overall is minimal if non-existent.

There is evident need for improvements in EOL practice and education and without this EOL care for the dying, they will continue to be deprived.

\section{CONCLUSION}

It has been highlighted whether dying can always be a positive experience for all. The publication of LACDP 'One Chance to Get it Right (2014) guidance and excellent standards of care, is the vision of EOL care and this is the expected outcome of those who die in the UK. The LCP had shown previous support for good care of dying people, a persistent concern was that when poor care of dying people was delivered with use of the LCP, the problems were with how the LCP had been interpreted rather than the LCP document; there was a subsequent call for an increase in training and education for healthcare staff to improve care for dying people by the publication of new guidance (LACDP, 2014). 
The new guidance published in caring for dying patients appears non-prescriptive and extensively differs from guidance that many staff may have been accustomed to.

There is evident need for improvements in EOL practice and education and without this EOL care for the dying, they will continue to be denied. Further research into the training needs and requirements of staff who care for the dying is required in an attempt to provide further insight into EOL care and to enable provision at an excellent standard.

\section{REFRENCES}

Addicott R, Ashton, R (2010) The King's Fund, Delivering better care at end of life. The next steps. Retrieved from: http://www.kingsfund.org.uk/sites/files/kf/Delivering-bettercare-end-of-life-Kings-Fund-January-2010-Leeds-Castle-EOLC.pdf

Bunn R (2014) Palliative care pharmacist defends Liverpool Care Pathway for dying patients. The pharmaceutical Journal, 292, (7809/10), p49.

Chinthalpalli K (2013) The Liverpool care pathway: what do specialists think? The British medical journal. 346, f1184.

Chiplasky LM (2015) End-of-life-care: are nurses educationally prepared? Journal of nursing. Retrieved from: http://rnjournal.com/journal-of-nursing/end-of-life-care-are-nurseseducationally-prepared

Department of Health (2008) End of Life Care Strategy: promoting high quality care for adults at the end of their life. London: DH Publications. 
Duxbury J, O'Brien T, Pulsford D, Yates S, Ellis H, Hacking S, Mathiesen M, Sheik K, Dedman D, Jackson G (2011) Scoping exercise of end of life education and training for health and social care staff in the north west. Everybody's business, getting it right first time. NHS North West \& University of Central Lancashire.

Ferrell B, Virani R, Paice J.A, Coyle N, Coyne P (2010) Evaluation of palliative care nursing education seminars. European journal of oncology nursing, 14 (74-79).

Ford, S (2014) Nurses lack skills in end of life care. Retrieved from:

http://www.nursingtimes.net/nursing-practice/clinical-zones/end-of-life-and-palliativecare/nurses-lack-skills-in-end-of-life-care/5022455.article

Ford, S (2014) RCN Survey raises profound concerns about care of the dying. Retrieved from:http://www.nursingtimes.net/nursing-practice/specialisms/end-of-life-andpalliative-care/rcn-survey-raises-profound-concerns-about-care-ofdying/5076375.article

Freemantle A, and Seymour J (2012) Why is the Liverpool care pathway used for some dying cancer patients and not others? Healthcare professionals' perspectives. Biomedcentral-researchnotes. 5:524. Retrieved from: http://www.biomedcentral.com//756-0500/5/524

GMC (2010) Treatment and Care Towards the End of Life: Good Practice in Decision Making. Retrieved from: http://www.gmcuk.org/guidance/ethical guidance/end of life care.asp 
Handy J.M, Dharmadasa A, and Soni, N (2013) The future of the Liverpool care pathway in caring for the dying in intensive care. Journal of intensive care society, 14 (2) (100102.

Hughes-Hallet T, Murray S, Cleary J, Grant L, Harding R, Jadad A, Steedman M, \& Taylor K (2012) Dying Healed: Transforming end of life care though innovation - Report of end of life care working group.

Jeffery D (2006) Communication. In Fallon, M., and Hanks, G. (2 ${ }^{\text {nd }}$ Eds.), $A B C$ of palliative care (pp52-55). Oxford: BMJ Books-Blackwell Publishing.

Jones ALC (2008) Fear in recognising the dying patient, British journal of medicine. 336: 958 retrieved from: doi: http://dx.doi.org/10.1136/bmj.39535.491238.94

Kirchoff KT (2000) Critical care nurses perceptions of obstacles and helpful behaviours in providing end of life care to dying patients. American journal of critical care, 9 (2) 96105. Retrieved from: http://ajcc.aacnjournals.org/content/14/5/395.full.pdf+html

Lawton J (2000) The Dying Process: Patient experiences of palliative care. UK: Routledge

Leadership Alliance for the Care of Dying People (2014). 'One Chance to get it right'. Improving people's experience of care in the last few days and hours of life: Leadership Alliance for the Care of Dying People.

Maguire P, Pitceathly C (2002) Key communication skills and how to acquire them. British medical journal. 325 (28) 697-700. 
Meldrum (2005) cited in Seymor J (2012) Looking back, looking forward: the evolution of palliative care and end-of-life care in England. Mortality. 12 (1) 1-13.

Morris J, Corbett A (2011) Communication skills training in end-of-life care. Nursing times, 107 (47) 16-17.

Neuberger, J (2003) cited in Ellershaw J \& Ward C (2003) Clinical review - Care of the dying patient: the last hours or days of life. British medical journal, 326 (4) 30-34.

National End of Life Care Intelligence Network (2015). Sage and Thyme Level 1 communication skills training. Cumbria and Lancashire end of life network. Retrieved from:

http://www.endoflifecumbriaandlancashire.org.uk/info health socialcare professional s/comms skills training/SageandThyme.php

NICE (2013) End of life Care for Adults: Quality Standard 13. Retrieved from: https://www.nice.org.uk/guidance/qs13

NHS (2014). National end of life care programme-Transforming end of life care in acute hospitals. Retrieved from: http://www.nhsiq.nhs.uk/improvement-programmes/longterm-conditions-and-integrated-care/end-of-life-care/acute-hospital-care.aspx

Oransky I (2005) Dame Cicely Mary Strode Saunders, The Lancet. 366 (9486), 628. 
Payne S, Turner M \& O'Brien T (2009) Exploring staff attitudes to undertaking advanced communication skills training. Retrieved from:

http://www.lancaster.ac.uk/shm/research/ioelc/programmes/documents/comms-skillsreport.pdf

Pentaris P (2013) Healthcare practitioners and dying patients. Journal of education, culture and society. 1 (2013) 38-43.

Saunders C (1993) cited in Mehta A \& Chan LS (2008) Understanding the concept of 'total pain': a prerequisite for pain control. Journal of hospice and palliative nursing. 10 (1), 26-32.

Saunders C (2005) Cicely Saunders - Founder of the Hospice Movement: Selected Letters 1959-1999. New York: Oxford University Press.

Sleeman K E (2013) EOL Communication: Let's talk about death. RCPE 43: 197-9

Storey cited in Sprinks J (2011). Nurses lack confidence in end of life care. Nursing older people, $23(2)$

6-7.

Stephenson J (2014) Liverpool pathway continues to be used, claims palliative care academic. Retrieved from: http://www.nursingtimes.net/nursingpractice/specialisms/end-of-life-and-palliative-care/liverpool-pathway-continues-tobe-used-claims-palliative-care-academic/5075230.article

Taylor K (2014) Transforming care at the end of life - Dying well matters. London: Deloitte UK centre for health solutions. 
The Economist (2010) Quality of death: a ranking of care of the dying by country. The Economist; online extra. Retrieved from: www.Tinyurl.com/EconomistQualityofDeath

The Mid Staffordshire NHS Foundation Trust Public Inquiry. (2013). Report of the Mid Staffordshire NHS Foundation Trust Public Inquiry, Chaired by Robert Francis QC. London: The Stationery Office.

Thorns and Garrard (2003) cited in Ellershaw, J. and Wilkinson, S. (2013). Care of the dying: a pathway to excellence. Oxford: Oxford University Press.

Wood J, \& Salter F (2013) Sue Ryder - A time and a place. What people want at the end of life. Retrieved from: http://www.sueryder.org/ /media/Files/About-us/A-Time-and-aPlace-Sue-Ryder.ashx

World Health Organisation (1990). As cited in Seymor, J. (2012). Looking back, looking forward: the evolution of palliative care and end-of-life care in England. Mortality, 12 (1) 1-13.

Wrigley A (2014) An ethical defence of the Liverpool care pathway. Nursing times. 110 (40) 20-21 


\section{CPD QUESTIONS}

- Reflect on your $1^{\text {st }}$ experience of death within practice as a nurse, how did this make you feel? Try using a reflective model to assist in refelection.

- Reflect upon the EOL education you received prior \& whilst you have been in practice, has this prepared you? Did this prepare you for your $1^{\text {st }}$ experience?

- Explore how the new guidance has been implemented into your area of practice. Plan how you would use this if it was to be utilised with a dying patient.

- Review Cicely Saunders Total Pain Theory \& how this has impacted on clinical guidance of today. As $\Omega_{\text {s }}$ the WHO three step pain ladder in symptom management that was initiated by Cicely Saunders \& Twycross (1977). 